NASA Technical Memorandum 107456

\title{
Thin Film Multilayer Conductor/Ferroelectric Tunable Microwave Components for Communication Applications
}

Félix A. Miranda, Robert R. Romanofsky and Frederick W. Van Keuls

Lewis Research Center

Cleveland, Ohio

Carl H. Mueller, Randolph E. Treece, and Tania V. Rivkin $S C T$

Golden, Colorado

Prepared for the

9th International Symposium on Integrated Ferroelectrics sponsored by the University of Colorado

Santa Fe, New Mexico, March 2-5, 1997

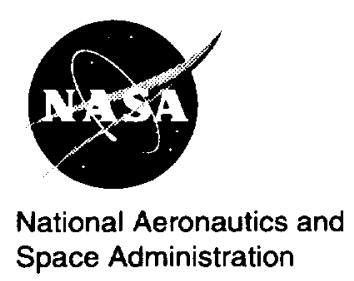


$\cdot$ 


\title{
THIN FILM MULTILAYER CONDUCTOR/FERROELECTRIC TUNABLE MICROWAVE COMPONENTS FOR COMMUNICATION APPLICATIONS
}

\author{
FELIX A. MIRANDA ${ }^{\mathrm{a}}$, ROBERT R. ROMANOFSKY ${ }^{\mathrm{a}}$, \\ FREDERICK W. VAN KEULS ${ }^{\mathrm{a}}$, CARL H. MUELLER ${ }^{\mathrm{b}}$, \\ RANDOLPH E. TREECE ${ }^{b}$, and TANIA V. RIVKIN ${ }^{b}$ \\ ${ }^{a}$ NASA Lewis Research Center, Cleveland, Ohio, 44135, USA; \\ bSCT, Golden, Colorado, 80401, USA
}

A study of $\mathrm{Au} / \mathrm{SrTiO}_{3} / \mathrm{YBa}_{2} \mathrm{Cu}_{3} \mathrm{O}_{7-\delta} / \mathrm{LaAlO}{ }_{3}$ and $\left(\mathrm{Au}, \mathrm{YBa}_{2} \mathrm{Cu}_{3} \mathrm{O}_{7-\delta}\right) /$ $\mathrm{Ba}_{\mathrm{x}} \mathrm{Sr}_{1-\mathrm{x}} \mathrm{TiO}_{3} / \mathrm{LaAlO}_{3}(\mathrm{x}=0,0.50$, and 0.40$)$ multilayered structures is presented. At $1.0 \mathrm{MHz}$, the largest tuning of $\mathrm{Au} / \mathrm{SrTiO}_{3} / \mathrm{YBa}_{2} \mathrm{Cu}_{3} \mathrm{O}_{7-\delta}$ parallel plate capacitors corresponded to single-phased, epitaxial $300-$ $500 \mathrm{~nm}$ thick $\mathrm{SrTiO}_{3}$ thin films deposited at $800^{\circ} \mathrm{C}$. For $\mathrm{SrTiO}_{3} / \mathrm{LaAlO}_{3}$ structures having $\mathrm{SrTiO}_{3}$ films of similar quality, we observed that at $1.0 \mathrm{MHz}$ and $77 \mathrm{~K}$, interdigital capacitors exhibit higher tunabilities and lower losses than parallel plate configurations, but required higher dc voltage. For a $300 \mathrm{~nm}$ thick $\mathrm{SrTiO}_{3}$ film, a $25 \Omega \mathrm{YBa}_{2} \mathrm{Cu}_{3} \mathrm{O}_{7-\delta} / \mathrm{SrTiO}_{3}{ }^{\prime}$ $\mathrm{LaAlO}_{3}$ phase shifter exhibited a phase shift $\sim 2.6$ times larger than its $\mathrm{Au} / \mathrm{SrTiO}{ }_{3} / \mathrm{LaAlO}_{3}$ counterpart. At $19 \mathrm{GHz}$ and $32 \mathrm{~V}$, a $360^{\circ}$ phase shift could in principle be achieved with coupled microstripline sections only $7.0 \mathrm{~mm}$ long. At $14 \mathrm{GHz}, 77 \mathrm{~K}$ and $260 \mathrm{~V}$, for $1.0 \mu \mathrm{m}$ and $300 \mathrm{~nm}$ thick $\mathrm{SrTiO}_{3}$ films, $25 \Omega 360^{\circ} \mathrm{Au} / \mathrm{SrTiO}_{3} / \mathrm{LaAlO}_{3}$ phase shifters would be nominally $4.0 \mathrm{~mm}$ and $12 \mathrm{~mm}$ long, respectively. For a $2 \lambda \mathrm{YBa}_{2} \mathrm{Cu}_{3}$ $\mathrm{O}_{7-\delta} \mathrm{SrTiO}_{3} / \mathrm{LaAlO}_{3}$ ring resonator a tuning rate of $0.7 \mathrm{MHz} / \mathrm{Volt}$ was achieved at $10 \mathrm{GHz}$ and $77 \mathrm{~K}$. The relevance of these structures for phased array antennas and as tunable elements in discriminator-stabilized oscillators is discussed. 
Keywords: (HTS,metal)/ferroelectric structures; tunable microwave components; dielectric constant; loss tangent; parallel plate and interdigital capacitors; phase shifters; ring resonators.

\section{INTRODUCTION}

Improvements in the quality of ferroelectric thin films have prompted their usage in proof-of-concept (POC) tunable microwave components such as varactors, phase shifters, and filters, amongst others. ${ }^{[1-3]}$ For practical microwave applications, issues such as optimization of the dielectric properties of the ferroelectric films, device configuration (i.e., parallel or interdigital), and degree of tunability versus losses, amongst others, must be addressed.

In the area of satellite communications, congestion of the frequency spectrum at and below the Ku-band resulting from the boom of the wireless communication industry, has prompted utilization of higher frequency bands such as the $\mathrm{K}$ - and $\mathrm{Ka}$-band. Phased array antennas have been identified as a critical component for many of the proposed satellite constellations (e.g., Teledesic) targeted for operation by the turn of the century ${ }^{[4]}$. Hence, compact, low loss phase shifters will be an enabling component for these applications. In addition, small, low cost, low-phase noise local oscillators (LO) which are compatible with high order, bandwidth efficient modulation schemes (e.g., QPSK) are required.

In this paper, we report on our study of gold/ $/ \mathrm{SrTiO}_{3} / \mathrm{YBa}_{2} \mathrm{Cu}_{3} \mathrm{O}_{7-\delta}$ $\mathrm{LaAlO}_{3}(\mathrm{Au} / \mathrm{STO} / \mathrm{YBCO} / \mathrm{LAO})$ and $\left(\mathrm{gold}, \mathrm{YBa}_{2} \mathrm{Cu}_{3} \mathrm{O}_{7-\delta}\right) / \mathrm{Ba}_{\mathrm{x}} \mathrm{Sr}_{1-\mathrm{x}} \mathrm{TiO}_{3} /$ $\mathrm{LaAlO}_{3}(\mathrm{x}=0,0.50$, and 0.40$)((\mathrm{Au}, \mathrm{YBCO}) / \mathrm{BSTO} / \mathrm{LAO})$ multilayered structures. The effect of the deposition temperature of the ferroelectric film on the tuning and losses of parallel plate capacitors at $1.0 \mathrm{MHz}$ is discussed. Dependence of tuning and losses on the geometry of the tunable components is presented. As a demonstration of the great potential of these components for advantageous insertion into satellite and groundbased communication systems, we present results of proof-of-concept (POC) coupled microstripline phase shifters (CMPS) and interdigital ring resonators for $\mathrm{LO}$ between the $10-20 \mathrm{GHz}$ frequency range. 


\section{EXPERIMENTAL}

The multilayer structures considered in this study were deposited in-situ on (100) LAO single-crystal substrates (254 and $508 \mu \mathrm{m}$ thick) by pulsed laser deposition (PLD). The dielectric properties of the STO films in the Au/STO/YBCO parallel plate configuration were studied by varying the deposition temperature of the ferroelectric film from $825^{\circ}$ to $250^{\circ} \mathrm{C}$. For all these structures the YBCO films were deposited at $800{ }^{\circ} \mathrm{C}$. For this part of the study, the STO films were $300-500 \mathrm{~nm}$ thick, and the YBCO films were $\sim 350 \mathrm{~nm}$ thick. The parallel plate capacitor used in this study is similar to that used previously; ${ }^{[5,6]} \mathrm{Au}$ electrodes $(\sim 2.5 \mu \mathrm{m}$ thick) were used. For the interdigital configurations we used Au and platinum (Pt) electrodes, $0.5 \mu \mathrm{m}$ thick. In this configuration we also examined BSTO films which were also deposited by PLD and were $\sim 500 \mathrm{~nm}$ thick. The electrodes were deposited by electron beam (e-beam) evaporation. A $15 \mathrm{~nm}$ thick titanium or chromium adhesion layer was e-beam evaporated before the metal deposition. Standard photolithography techniques and chemical etching (lift-off) were used to fabricate these structures. The crystal structure and surface topology of the ferroelectric films were analyzed by X-Ray Diffraction (XRD) and Atomic Force Microscopy (AFM), respectively.

At low frequencies (i.e., $1.0 \mathrm{MHz}$ ), the electrical response of the multilayer structures was studied by measuring the dielectric constant $\left(\varepsilon_{\mathrm{r}}\right)$ and loss tangent $(\tan \delta)$ of the ferroelectric film as a function of temperature (300-20 K), at ac voltages within $5-100 \mathrm{mV}$, and at dc electric fields from zero to $1.0 \times 10^{5} \mathrm{~V} / \mathrm{cm}$ for the parallel plate capacitors, and up to $3.5 \times 10^{5} \mathrm{~V} / \mathrm{cm}$ for the interdigital configurations. An HP 4192A LF Impedance Analyzer coupled through bias lines to the second stage of a closed-cycle helium gas refrigerator was used to perform these measurements. The measurement system was fully automated and controlled by an HP 900-300 computer. Characterization of the coupled microstripline phase shifters and the interdigital ring resonators at frequencies between $10-20 \mathrm{GHz}$ was performed using an HP 8510C automatic network analyzer (ANA) coupled through semi-rigid input/ output coaxial cables to the second stage of a closed-cycle helium gas refrigerator similar to the one mentioned above. All the measurements were performed under a vacuum of less than 10 mtorr. 


\section{RESULTS}

Figure 1 shows data on $\varepsilon_{\mathrm{r}}$ and $\tan \delta$ for a Au/STO/YBCO parallel plate capacitor with the STO film deposited at $800{ }^{\circ} \mathrm{C}$. The area for the $\mathrm{Au}$ electrodes was $400 \times 400 \mu \mathrm{m}^{2}$ and the STO film was $300 \mathrm{~nm}$ thick. In this study we found that the largest tuning corresponds to the structures with the $800^{\circ} \mathrm{C}$ STO films. As reported previously, we have observed that higher deposition temperatures resulted in interfacial degradation and poor film quality, while lower deposition temperatures resulted in films with lower dielectric constants, lower tunabilities, and higher losses. ${ }^{[7]}$ Similar results were also obtained for film thicknesses near $500 \mathrm{~nm}$. For STO films deposited at temperatures near $800^{\circ} \mathrm{C}, \mathrm{XRD}$ scans showed that the films were (100) oriented and singled-phased. Thus, maximum tuning of the Au/STO/YBCO structure can be attained with single-phased, epitaxial 300-500 nm thick STO films deposited at $800^{\circ} \mathrm{C}$. As shown in figure 1 , the $\tan \delta$ for these films was typically $\sim 0.05$ for temperatures below $80 \mathrm{~K}$, and was insensitive to changes in dc bias. However, we have observed that the parallel plate structure is influenced by electrical shorts in the ferroelectric film which are in turn associated with the roughness of the YBCO film. ${ }^{[6,8]}$ Thus, improving the smoothness of the underlying YBCO layer may help in reducing the electrical shorts in the ferroelectric layers.

The dielectric properties of the interdigital structures investigated were significantly different from those of the parallel plate capacitors. Several capacitor dimensions were studied; in general the gaps between the electrodes and the finger width were either 10 or $20 \mu \mathrm{m}$, the number of
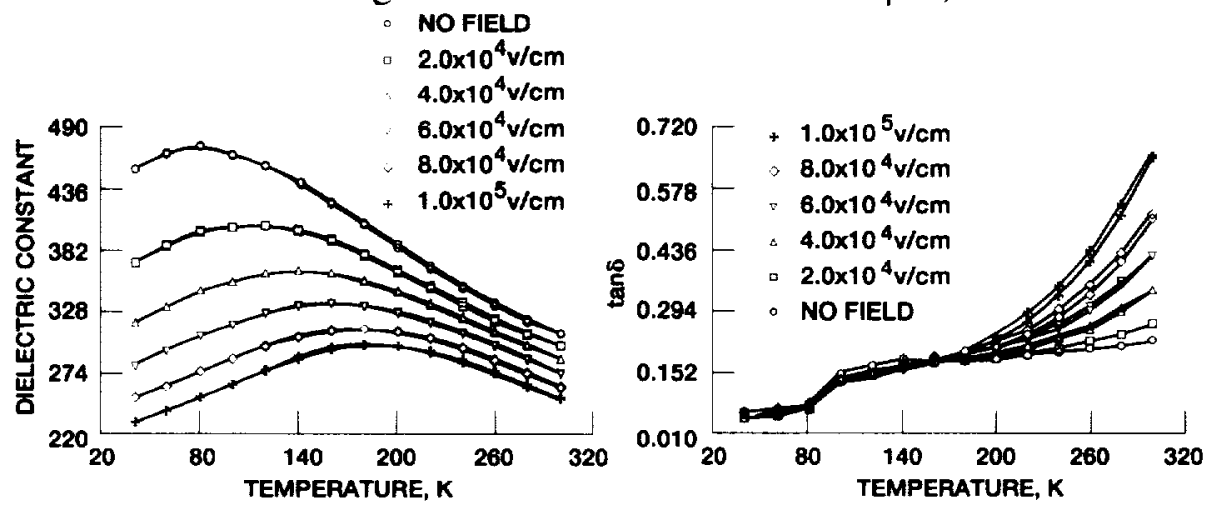

Figure 1 Dependence of $\epsilon_{r}$ and $\tan \delta$ on temperature and applied de field for the STO film in a Au/STO/ YBCO parallel plate capacitor. The STO film $(300 \mathrm{~nm})$ was deposited at $800^{\circ} \mathrm{C}$. The YBCO and AU electrodes are $350 \mathrm{~nm}$ thick and $2.5 \mu \mathrm{m}$ thick, respectively. Data are shown for the cooling and warming cycles and were taken at $1.0 \mathrm{MHz}$. The contact area was $400 \mu \mathrm{m} \times 400 \mu \mathrm{m}$. 


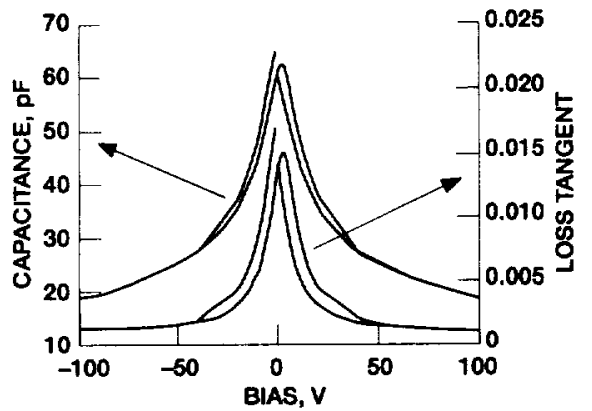

FIGURE 2 Capacitance and $\tan \delta$ as a function of dc voltage for an interdigital Au/STO/AO structure. The data were taken at $1.0 \mathrm{MHz}$.

interdigital fingers varied from 13 to 50 , and the finger length was always $1.0 \mathrm{~mm}$. Figure 2 shows the capacitance and $\tan \delta$ of a $\mathrm{Au} / \mathrm{STO} / \mathrm{LAO}$ interdigital capacitor at $77 \mathrm{~K}$ and $1.0 \mathrm{MHz}$. Note that the degree of tuning and the $\tan \delta$ values are larger and smaller, respectively, than those corresponding to parallel plate capacitors, although larger values of $\mathrm{dc}$ bias are required for the interdigital configuration. For example, a tuning of $47 \%$ was attained at $80 \mathrm{~K}$ for the sample shown in figure 1 by applying a dc bias of just $5 \mathrm{~V}$, while for the interdigital capacitor a tunability of $70 \%$ was observed at a dc voltage of $50 \mathrm{~V}$. The loss behavior of the STO film in the interdigital structure was attributed to defects intrinsic to the STO whereas for the film in the parallel plate capacitor they were mainly dominated by electrical shorts of the YBCO through the STO film. Figure 3 shows the capacitance as a function of temperature and dc bias for Au/STO/LAO and Pt/BSTO/LAO (Ba:Sr;0.50:0.50) interdigital capacitors at $1.0 \mathrm{MHz}$. Observe that the point of maximum tuning

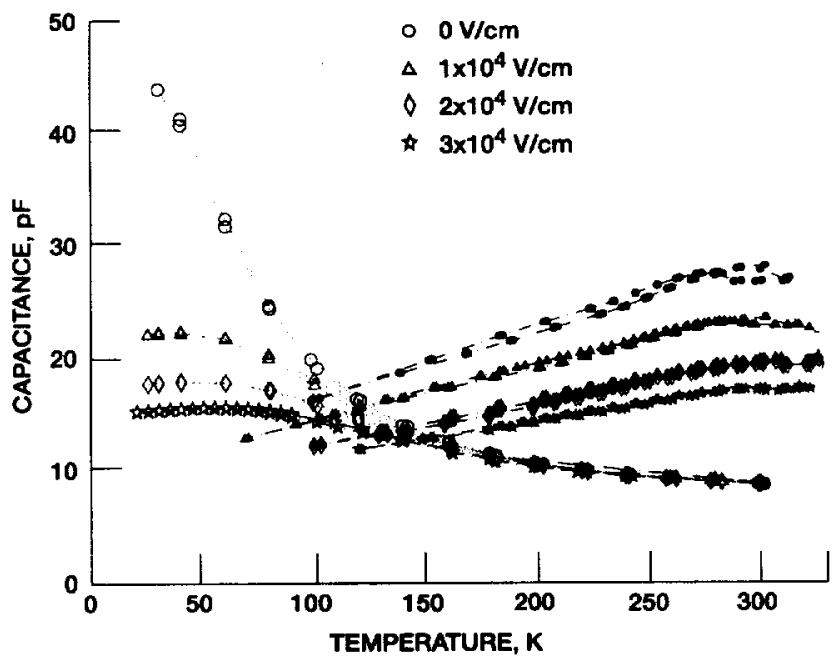

FIGURE 3 Capacitance versus temperature, for soveral electric field intensities, for a Aw/STONAO interdigital capacitor (open symbols) and a PU/BSTO/LAO interdigital capacitor (solid symbols). The data were taken at $1.0 \mathrm{MHz}$. 
occurs at different temperatures. Therefore, applications at cryogenic temperatures could in principle be realized using STO films while those targeted for temperatures near or at room temperature could potentially be realized by using BSTO films.

Most of the studies on ferroelectric based structures heretofore have been performed at low frequencies. Table I shows a summary of some of these works, which provide data on $\varepsilon_{\mathrm{r}}$, $\tan \delta$, type of structure, percent of tunability $\left(\left(\left(\varepsilon_{\mathrm{r}}(0)-\varepsilon_{\mathrm{r}}\left(\mathrm{V}_{\max }\right)\right) / \varepsilon_{\mathrm{r}}(0)\right) \times 100=\left(\Delta \varepsilon_{\mathrm{r}} / \varepsilon_{\mathrm{r}}(0)\right) \times 100\right)$, and $\mathrm{K}$-factor $\left(\left(\Delta \varepsilon_{\mathrm{r}} / \varepsilon_{\mathrm{r}}(0)\right) / \tan \delta(0)\right)$, amongst others. The $\mathrm{K}$-factor is a figure of merit that allows the comparison of different samples in a meaningful way. Therefore, as part of our study we have examined the performance of the (Au,HTS)/STO/LAO structures at K-band frequencies. Figure 4 shows a schematic diagram of a $25 \Omega$ (with input/output 50 to $25 \Omega$ transformers), and $50 \Omega$ CMPS. For these phase shifters, the line capacitance was calculated by adapting the quasi-TEM variational expression of Koul and Bhat, ${ }^{[9]}$ and using the transmission line method of Crampagne, Ahmadpanah, and Guiraud. ${ }^{[10]}$ The coupled line structure was optimized to minimize loss and maximize phase shift. In doing so, we tried to capitalize in the fact that the thin ferroelectric film is most effective when the phase velocity $\left(V_{p}\right)$ is dominated by the odd mode fields. The propagation constant is given by,

$$
\beta=\omega / V_{p}=\left(\pi / \lambda_{\mathrm{o}}\right)\left[\left(\varepsilon_{\text {even }}\right)^{0.5}+\left(\varepsilon_{\text {odd }}\right)^{0.5}\right]
$$

where, $\lambda_{\mathrm{o}}$ is the free space wavelength, $\varepsilon_{\text {even }}=\mathrm{C}_{\mathrm{E}} / \mathrm{C}_{\mathrm{Eair}}$ and $\varepsilon_{\text {odd }}=$ $\mathrm{C}_{\mathrm{O}} / \mathrm{C}_{\mathrm{Oair}}$, and $\mathrm{C}_{\text {Eair }}$ and $\mathrm{C}_{\mathrm{Oair}}$ are obtained by replacing all dielectrics with air. Thus, by capitalizing on the odd mode propagation constant, coupled microstripline phase shifters could yield more phase shift per

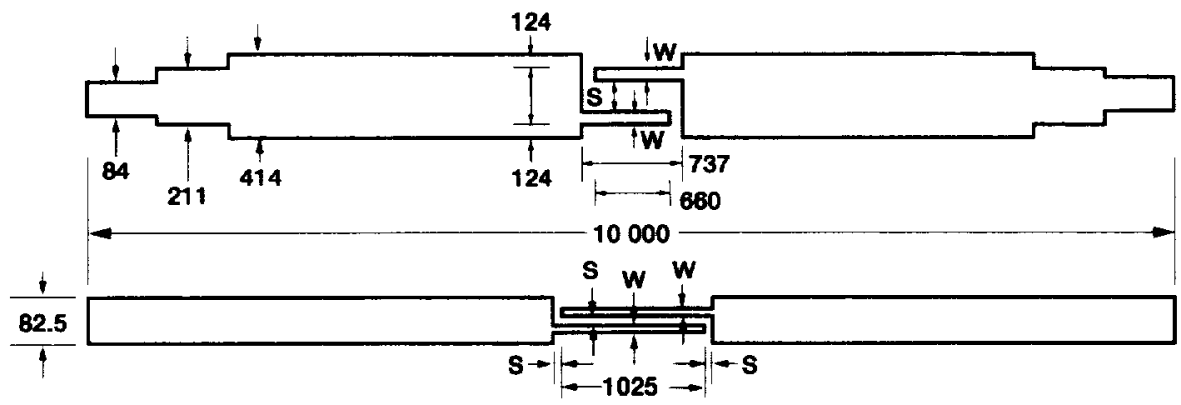

FIGUAE $4 \mathrm{Au}(1.5 \mu \mathrm{m}$ thick)/STO/AO(254 $\mu \mathrm{m}$ thick), microstrip transmission line with $20 \mathrm{GHz}$ bandpass interdigital section (with input/output 50 to 25 Ohms transformers). $S=12.7 \mu \mathrm{m}, W=76.2 \mu \mathrm{m}$. Bottom; $S=7.5 \mu \mathrm{m}, W=25 \mu \mathrm{m}$. All dimensions are in microns. 


\begin{tabular}{|c|c|c|c|c|c|c|c|c|c|c|c|}
\hline 递 & 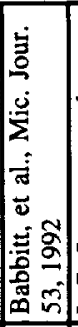 & 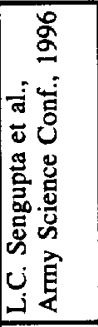 & 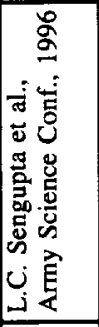 & 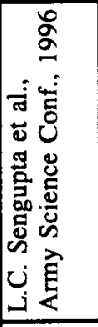 & 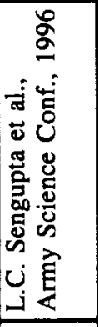 & 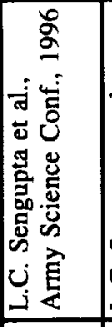 & 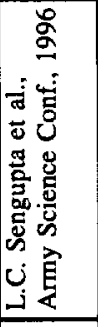 & 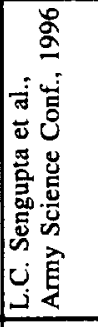 & 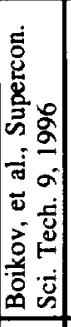 & 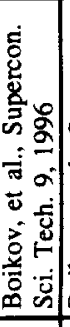 & 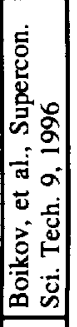 \\
\hline$\frac{9}{0}$ & 0 & $0^{\infty} \stackrel{.}{.}$ & $0 \infty$ & $0 \%$ & 00 & 0 & 0 & 0 & 0 & $\circ$ ○ & 100 \\
\hline 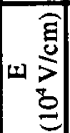 & $b$ & $0 \underset{j}{\circ}$ & 0 㝏 & 00 & 109 & 10 & 0 & 0 & 0 & 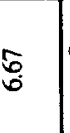 & 100 \\
\hline 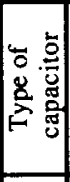 & & 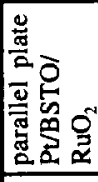 & 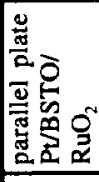 & 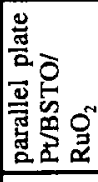 & 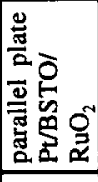 & 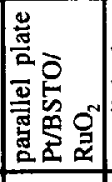 & 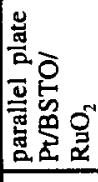 & 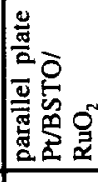 & 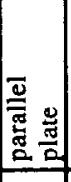 & 运 & 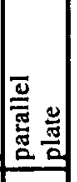 \\
\hline$\simeq$ 矛 & & & & $\ddot{\theta}$ & $\infty$ & & & & & $\stackrel{\partial}{m}$ & \\
\hline 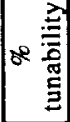 & & $\tilde{\omega}$ & 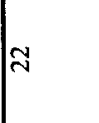 & हि & 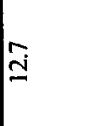 & & & & & $\infty$ & \\
\hline 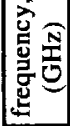 & f & $\begin{array}{l}0 \\
\hat{x} \\
a \\
0 \\
0\end{array}$ & $\begin{array}{l}0 \\
\frac{\partial}{x} \\
y \\
y\end{array}$ & $\mid \begin{array}{l}0 \\
\hat{x} \\
x \\
0 \\
0\end{array}$ & $\mid \begin{array}{l}0 \\
\frac{a}{x} \\
a \\
z\end{array}$ & $\stackrel{\partial}{\overrightarrow{\hat{\sigma}}}$ & 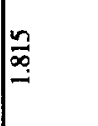 & $\begin{array}{l}\bar{\infty} \\
\vec{\gamma} \\
\vec{\gamma}\end{array}$ & $\mid \begin{array}{l}\overrightarrow{0} \\
\underline{\underline{x}} \\
\underline{x}\end{array}$ & $\underline{\underline{a}}$ & $\underline{\underline{x}}$ \\
\hline 我 & 8 & & & 产 & है & 串 & 害 & 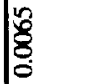 & $\overline{8}$ & 8 & 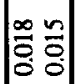 \\
\hline$\omega$ & $\&_{\infty}$ & 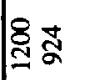 & హై & 95 & $\infty_{m}^{-\infty}$ & 话 & 芓 & $\cong$ & $\stackrel{\imath}{i}$ & 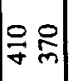 & 不 \\
\hline 跑 & : & $\stackrel{\infty}{2}$ & 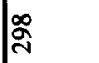 & సి & $\stackrel{\infty}{\nexists ~}$ & $\stackrel{2}{\approx}$ & $\stackrel{\infty}{\AA}$ & $\stackrel{\infty}{\stackrel{\infty}{~}}$ & $\stackrel{\leftrightarrow}{\stackrel{\leftrightarrow}{*}}$ & $E$ & 洛 ț \\
\hline $\mid$ & & 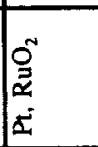 & 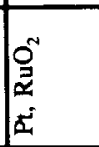 & 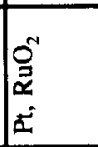 & 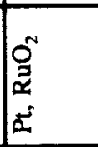 & 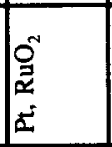 & 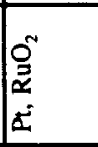 & 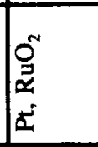 & 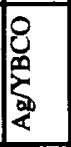 & 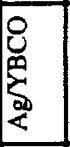 & 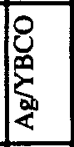 \\
\hline$\frac{\vec{\pi}}{\frac{\pi}{2}}$ & 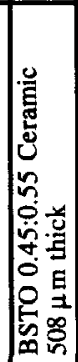 & 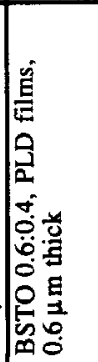 & 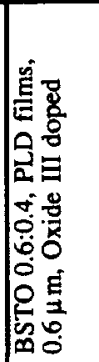 & 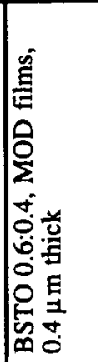 & 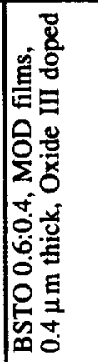 & 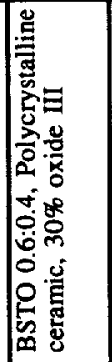 & 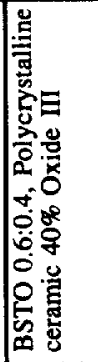 & 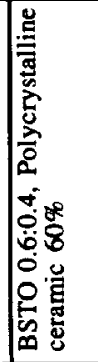 & 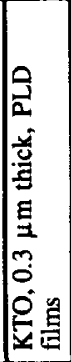 & 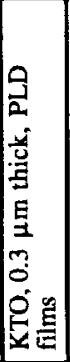 & 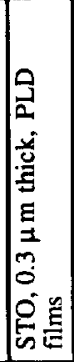 \\
\hline
\end{tabular}




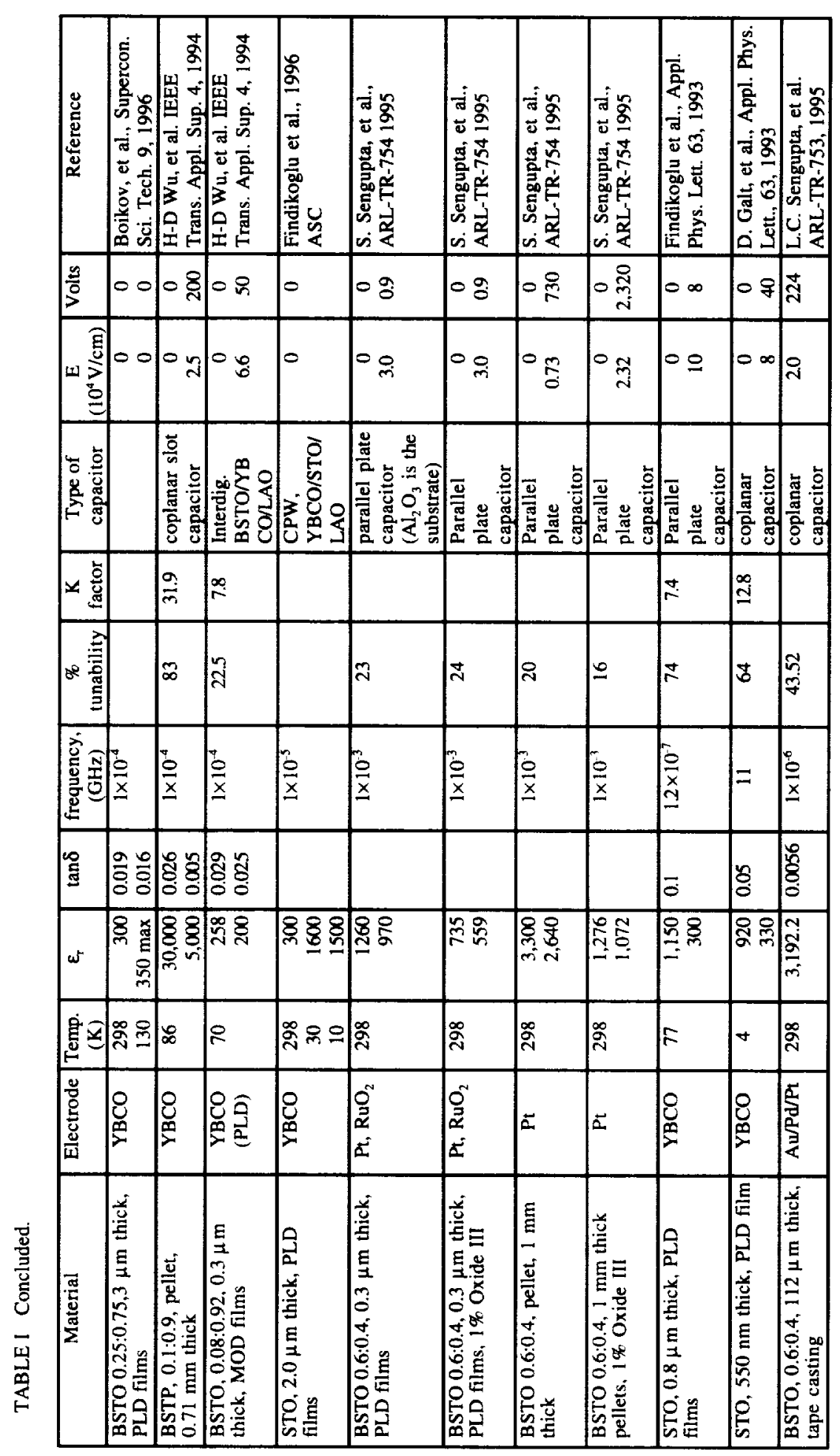




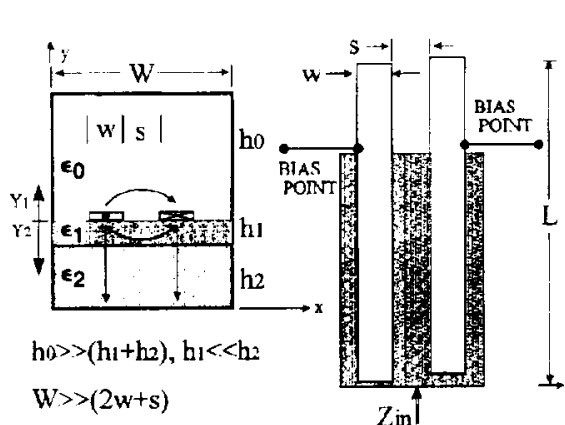

FIGURE 5 Coupled microstripline ferroelectric phase shifter.

unit length than simple microstrip lines while avoiding the need for a coplanar ground. The schematic shown in figure 5 summarizes our design approach.

Figure 6 shows experimental data, measured at $77 \mathrm{~K}$ and 19.4 GHz, for Au/STO(300 nm)/LAO and $\mathrm{YBCO} / \mathrm{STO}(300 \mathrm{~nm}) / \mathrm{LAO}$ CMPS. Note that a relative insertion phase shift $(\Delta \phi)$ of $\sim 13^{\circ}$ is attained with a dc bias of $32 \mathrm{~V}\left(2.5 \times 10^{4} \mathrm{~V} / \mathrm{cm}\right)$. By replacing the $\mathrm{Au}$ layer with a YBCO film, we obtained $\Delta \phi \sim 34^{\circ}$ at the same temperature, frequency and field. The raw insertion loss was less than $3 \mathrm{~dB}$. Since the coupling length of the CMPS is $0.66 \mathrm{~mm}$, this result implies that at 19 $\mathrm{GHz}$ and $32 \mathrm{~V}$, a $360^{\circ}$ phase shift could in principle be achieved with coupled microstripline sections only $7.0 \mathrm{~mm}$ long. Since this configuration relies in the odd mode propagation of the field across the ferroelectric film, we decided to investigate $\Delta \phi$ for thicker STO films. Figure 7 shows $\Delta \phi$ versus dc bias for Au/STO/LAO CMPS with $500 \mathrm{~nm}$ and 1.0 $\mu \mathrm{m}$ thick STO films. Note that for both samples there is a reversal of $\Delta \phi$ at a specific bias. This phase reversal can be explained in terms of change in $\varepsilon_{\mathrm{r}}$ with applied field. By modeling the structure using Sonnet em®

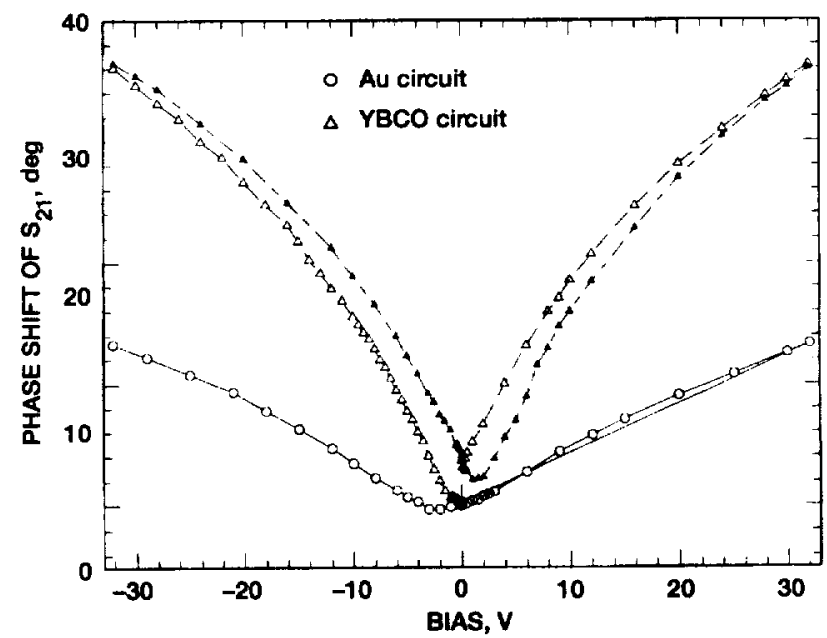

FIGURE 6 Au(1.5 $\mu \mathrm{m}) / S T O(300 \mathrm{~nm}) / L A O(254 \mu \mathrm{m})$ and YBCO(350 nm)/ STO(300 $\mathrm{nm}) / L A O(254 \mu \mathrm{m}) 25 \Omega$ coupled microstripline phase shifters. Open (solid) symbols denote increasing (decreasing) bias. The data were taken at $19.4 \mathrm{GHz}$. 


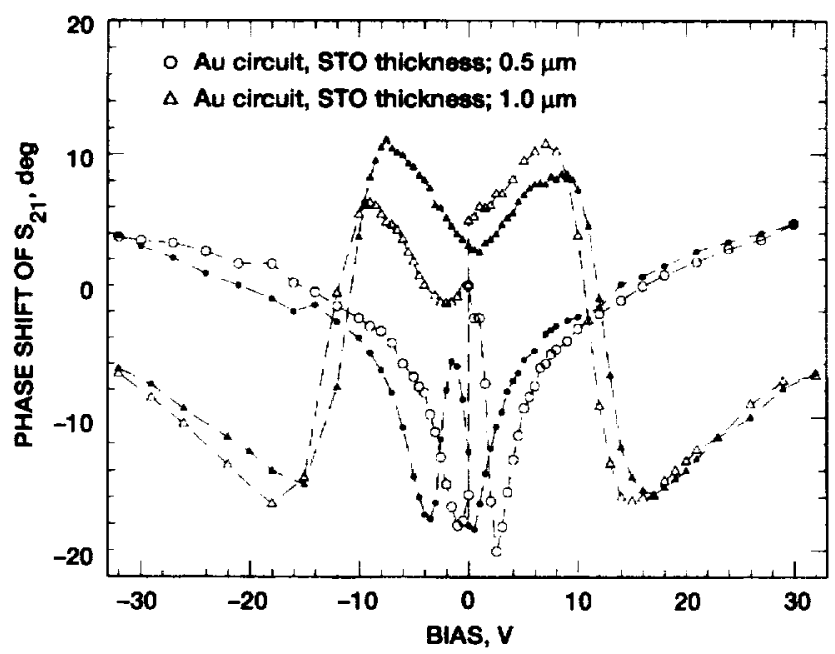

FIGURE 7 Au(1.5 umySTO/LAO(254 $\mu \mathrm{m}) 25 \Omega$ coupled microstripline phase shifters. Open (solid) symbols denote increasing (decreasing) bias. The data were taken at $20.455 \mathrm{GHz}$.

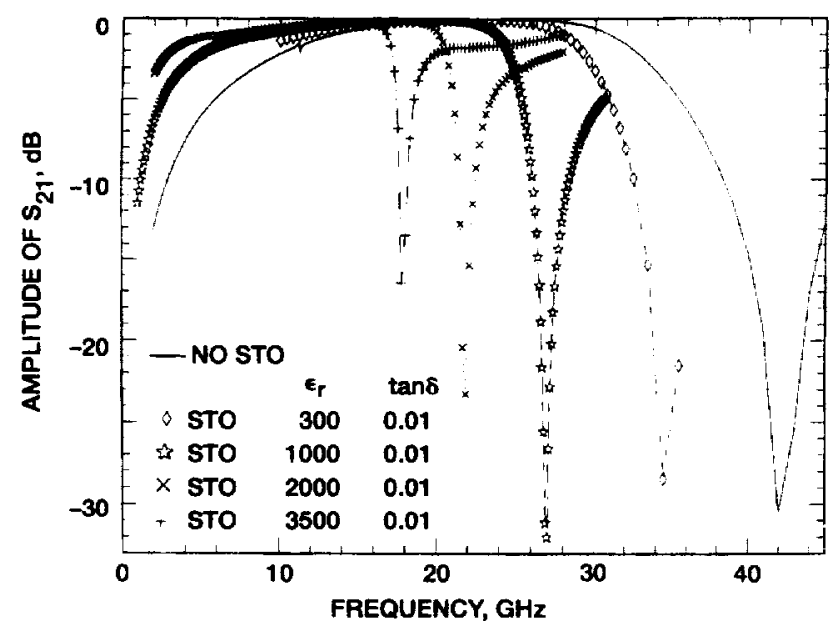

FIGURE 8 AU(1.5 $\mu \mathrm{m}) / \mathrm{STO}(300 \mathrm{~nm}) /$ AOO(254 $\mu \mathrm{m}) 50 \Omega$ coupled microstripline phase shifters: Sonnet emit simulation.

simulator, one can see that the bandpass of the CMPS is very broad in the absence of STO (see figure 8). Adding the STO layer $\left(\varepsilon_{\mathrm{r}}=300\right.$ ) to the structure, results in a narrowing of the passband, which compresses even more as the structure is cooled to cryogenic temperatures and $\varepsilon_{\mathrm{r}}$ for the STO layer increases $\left(\varepsilon_{\mathrm{r}} \sim 3500\right)$. Applying the dc bias results in lower values of $\varepsilon_{\mathrm{r}}$ with the concomitant shifting of the band edge to higher frequencies. Thus, the observed $\Delta \phi$ reversal for the $500 \mathrm{~nm}$ and $1.0 \mu \mathrm{m}$ films, results from the frequency of operation being at the band 


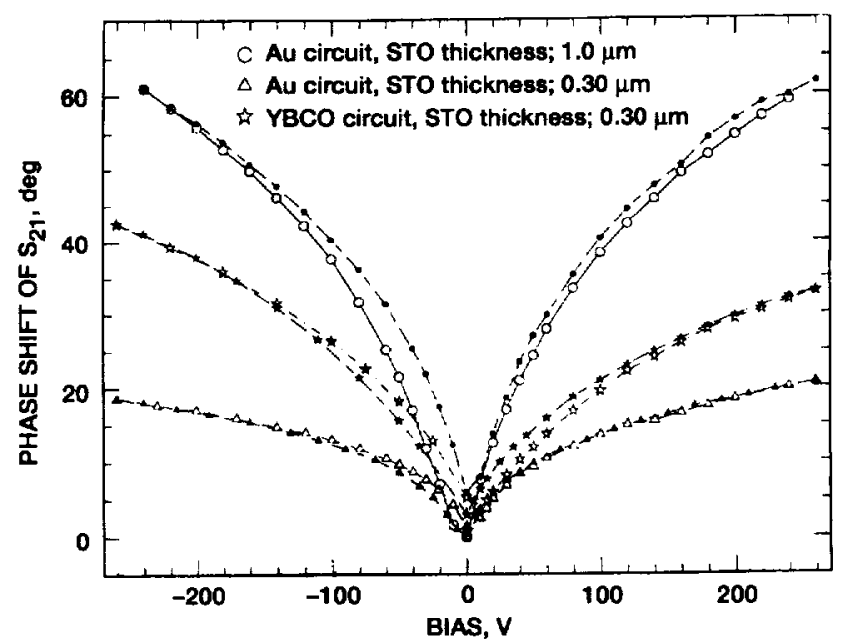

FIGURE $925 \Omega$ coupled microstripline phase shifters; T = 77K, frequency $=13.73 \mathrm{GHz}$. Open (solid) symbols denote increasing (decreasing) bias.

edge of the CMPS passband for a given bias value within the bias range considered in this study. Hence, for the CMPS under consideration one must be careful to operate within the passband, or at frequencies where the passband is insensitive to changes in $\varepsilon_{\mathrm{r}}$; figure 8 suggests that frequencies near $14 \mathrm{GHz}$ could satisfy this criteria. Figure 9 shows data taken at $77 \mathrm{~K}$ and $13.73 \mathrm{GHz}$ for Au/STO/LAO CMPS with STO films $300 \mathrm{~nm}$ and $1.0 \mu \mathrm{m}$ thick, respectively. Note that for $\left|\mathrm{V}_{\mathrm{dc}}\right| \leq 260 \mathrm{~V}, \Delta \phi$ increases monotonically without any reversal. Also for the $1.0 \mu \mathrm{m}$ film structure, $\Delta \phi$ is nearly three times larger than that measured for the structure with the $300 \mathrm{~nm}$ thick STO film. Thus, for the temperature, frequency, and bias stated above, a $360^{\circ}$ CMPS with a $1.0 \mu \mathrm{m}$ thick STO film could be nominally $4.0 \mathrm{~mm}$ long, and with a $300 \mathrm{~nm}$ thick STO the same CMPS would be nominally $12 \mathrm{~mm}$ long. These estimates assume that the passband would be maintained over the operating range. The experimental results obtained here are within less than a factor of two of the values for $\Delta \phi$ expected from theoretical predictions (see Table II).

TABLE II Theoretical insertion phase for coupled microstripline. $(\mathrm{w}=76.2 \mu \mathrm{m}, \mathrm{s}=12.7 \mu \mathrm{m}$ )

[Frequency $=13.0 \mathrm{GHz}, \mathrm{L}=660 \mu \mathrm{m}$ ]

\begin{tabular}{|c|c|c|}
\hline$\varepsilon_{\text {STo }}$ & $\Delta \phi\left(\mathrm{t}_{\text {STO }}=0.3 \mu \mathrm{m}\right) \mathrm{deg}$. & $\Delta \phi\left(\mathrm{t}_{\text {STO }}=1.0 \mu \mathrm{m}\right) \mathrm{deg}$. \\
\hline 200 & --- & --- \\
300 & 0.6 & 1.3 \\
2000 & 6.7 & 17.4 \\
3500 & 10.5 & 22.3 \\
5000 & 13.7 & 28.7 \\
\hline
\end{tabular}


Table III compare our results with those of others. Figure 9 also shows that, once again, replacing the Au film by the YBCO film resulted in larger $\Delta \phi$ values; this is presumably because of modified current distribution although more detailed analysis is required to fully account for this empirical behavior. As an additional advantage, $\tan \delta$ does not seems to be a significant hindrance for the implementation of these phase shifters at $\mathrm{K}$-band frequencies. Modeling of these structures by allowing $\tan \delta$ of the substrate (i.e., STO and LAO as a whole) to be as high a 0.1 , resulted in an insertion loss of less than $5 \mathrm{~dB}$ at $20 \mathrm{GHz}$ and $77 \mathrm{~K}$. For $700 \mathrm{~nm}$ thick BSTO (Ba:Sr; 0.4:0.6) thin films, the 25 $\Omega \mathrm{Au} / \mathrm{BSTO} / \mathrm{LAO}$ CMPS showed $\Delta \phi \sim 8^{\circ}-10^{\circ}$ at 296 and $200 \mathrm{~K}$, respectively, for $\left|V_{d c}\right|$ up to $160 \mathrm{~V}$. The marginal performance suggests that further optimization of this material is required.

We have also investigated the performance of contiguous and interdigital ring resonators fabricated using Au/STO/LAO and YBCO/ STO/LAO, respectively (figure 10). These resonators are intended for use in tunable discriminator-locked oscillators which could enhance the performance of LO for satellite communication systems, particularly by reducing the phase noise and consequently bit error rate (BER) degradation. ${ }^{[11,12]}$ Figure 11 shows the magnitude of the transmission $\left(S_{21}\right)$ and reflection $\left(S_{11}\right)$ scattering parameters for $A u / L A O$ and $\mathrm{Au} / \mathrm{STO} / \mathrm{LAO}$ ring resonators designed for operation at $20 \mathrm{GHz}$ and with dimensions as given in figure 10 . Observe that, as expected, there is slight shift in frequency $(\sim 2 \%)$ and a small increase (decrease) in insertion (return) loss due to the slight impedance change and loss tangent introduced by the STO layer. Figure 12 shows $S_{21}$ versus temperature

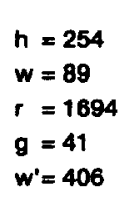

(a)

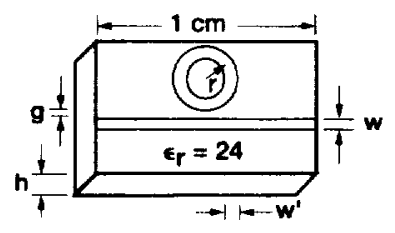

(b)

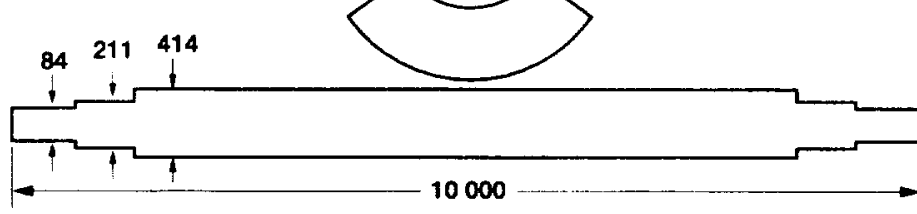

FIGURE 10 Aul $1.5 \mu \mathrm{m}$ thick)/STO ( $300 \mathrm{~nm}$ thick)/LAO (254 $\mu \mathrm{m}$ thick), $20 \mathrm{GHz}$ ring resonators, (a) $25 \mathrm{Ohm}$ ring, $50 \mathrm{Ohm}$ transmission line, (b) $25 \mathrm{Ohm}$ ring with interdigital gaps and input/output 50 to 25 Ohms transformer. All dimensions are in microns. 


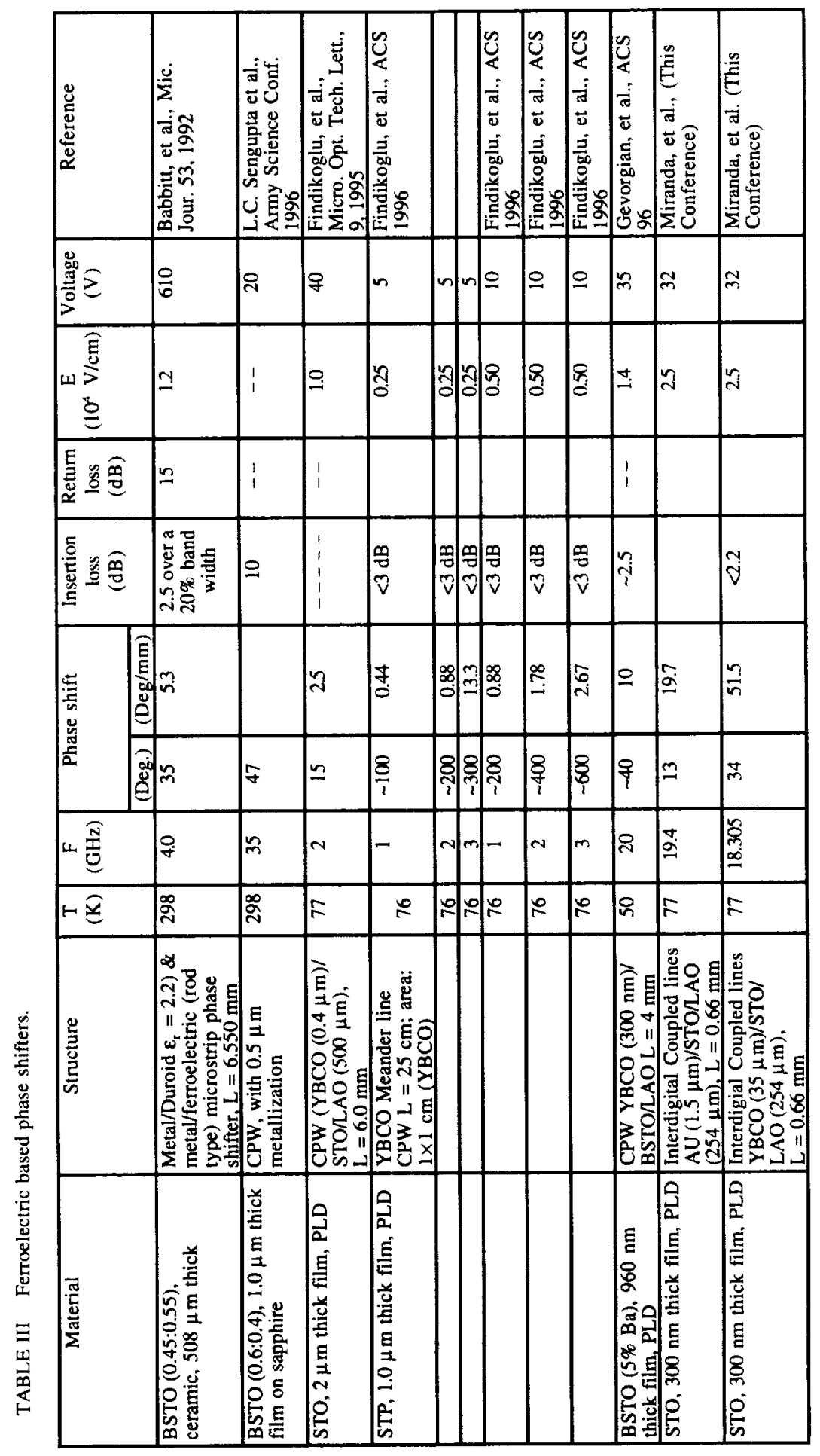



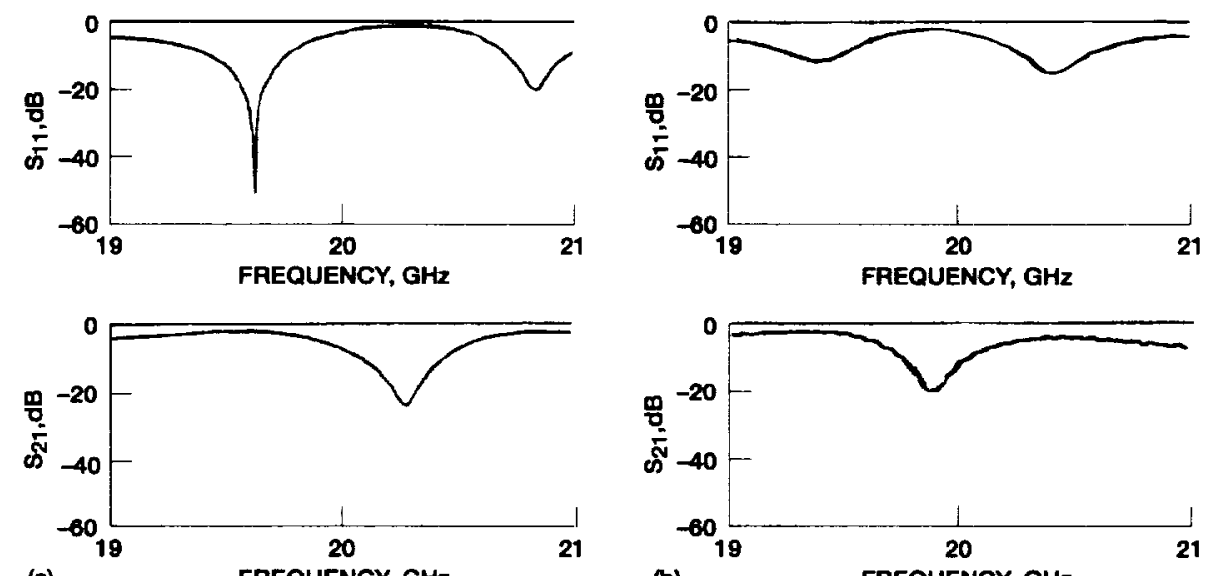

(a)

FREQUENCY, GHz

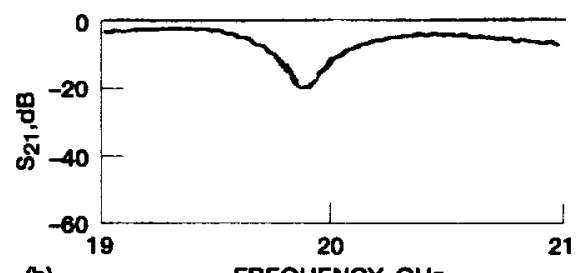

FIGURE 11 Transmission $\left(S_{21}\right)$ and reflection $\left(S_{11}\right)$ scattering parameters for (a) Au(1.5 $\mu \mathrm{m} \mathrm{v}$ LAO $(254 \mu \mathrm{m})$ and (b) Au(1.5 $\mu \mathrm{m}) / S T O(300 \mathrm{~nm}) / L A O(254 \mu \mathrm{m}) 25 \mathrm{Ohm}$ ring resonators at room temperature. The power level was $10 \mathrm{dBm} . \Delta \mathrm{F}=2 \%, F=$ resonant frequency.
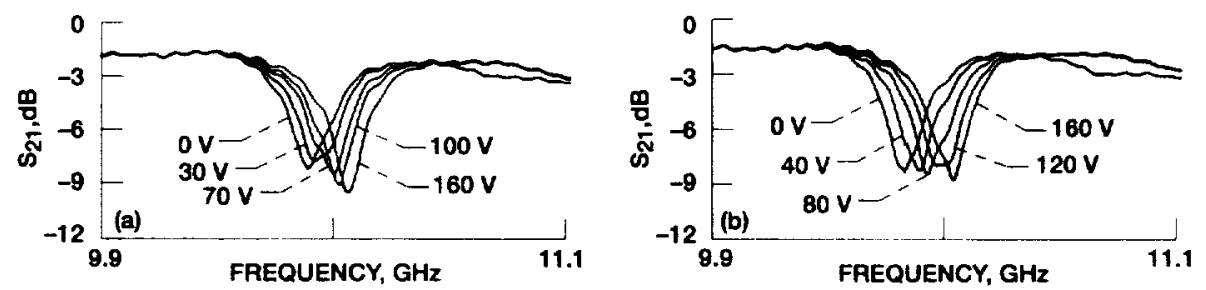

FIGUAE 12 YBCO $(350 \mathrm{~nm}) / \mathrm{STO}(300 \mathrm{~nm}) / L A O(254 \mu \mathrm{m}) 25 \Omega, 2 \lambda$ ring resonators; (a) $77 \mathrm{~K}$, (b) $50 \mathrm{~K}$.

for a YBCO/STO $(300 \mathrm{~nm}) / \mathrm{LAO} 25 \Omega, 2 \lambda$, interdigital ring resonator at $10 \mathrm{GHz}$. At $77 \mathrm{~K}$, the resonant frequency of the resonator shifted by $110 \mathrm{MHz}$ with a $160 \mathrm{~V} \mathrm{dc}$ bias; at $50 \mathrm{~K}$, the frequency shift was $\sim 160 \mathrm{MHz}$. This resonator exhibited loaded and unloaded Q's of 54 and 110 , respectively, at no bias, and of 55 and 160 at $160 \mathrm{~V}$, as calculated using the method of Khanna and Garault. [13]

\section{CONCLUSIONS}

We have reported on the characterization of (metal, HTS)/STO/YBCO and (metal)/BSTO/LAO thin film multilayer structures in terms of the dielectric properties of the ferroelectric layer at frequencies up to $20 \mathrm{GHz}$. We have observed that the largest tuning of the Au/STO/YBCO parallel plate capacitors corresponds to single-phased, epitaxial 
$300-500 \mathrm{~nm}$ thick STO films deposited at $800^{\circ} \mathrm{C}$. Although the STO films in parallel plate configuration can be tuned with low dc bias $(0-5 \mathrm{~V})$, their performance is limited by the high effective $\tan \delta$. Higher $\mathrm{dc}$ voltages (tens of volts) are required to tune the interdigital structures, but their higher degree of tunability and lower $\tan \delta$ make them attractive for microwave applications. We have developed proof-of-concept coupled microstrip lines phase shifters at $20 \mathrm{GHz}$, with low insertion loss and promising insertion phase shift per unit length. Implementation of these phase shifters with YBCO microstriplines resulted in greater phase shift per unit length than their metallic counterparts, presumably because of modified current distribution. These phase shifters are competitive with solid state-switched phase shifters in terms of performance and size, and promise simplicity of fabrication and cost advantage. For $2 \lambda$ YBCO/STO ring resonators, unloaded $Q$ 's improved with bias and showed values of 110 and 160 at zero and $160 \mathrm{~V}$, respectively. For this resonator a tuning rate of $\sim 0.7 \mathrm{MHz} /$ Volt was achieved at $77 \mathrm{~K}$ and $10 \mathrm{GHz}$. This type of ring resonator can be incorporated as a tunable element in a discriminator-locked oscillator. Optimization of this configuration and ring resonator configurations is currently underway.

Acknowledgments

One of the authors (F.W.V.K) gratefully acknowledges the support of the National Research Council.

References

[1.] V.K. Varadan, D.K. Ghodgaonkar, V.V. Varadan, J.K. Kelly, and P. Glikerdas, Microwave Journal, 35, 116 (1992).

[2.] R.W. Babbit, T.E. Koscica, and W.C. Drach, Microwave Journal, 35, 63 (1992).

[3.] D. Galt, J.C. Price, J.A. Beall, and R.H. Ono, Appl. Phys. Lett., 63, 3079 (1993).

[4.] G. Gilder, Forbes ASAP, Oct. 10 (1994).

[5.] F.A. Miranda, C.H. Mueller, C.D. Cubbage, K.B. Bhasin, R.K. Singh, and S. D. Harkness, IEEE Trans. Appl. Supercond., 5, 3191 (1995).

[6.] F.A. Miranda, C.H. Mueller, G.A. Koepf and R.M. Yandrofski, Supercond. Sci. Technol., 8 , 755 (1995). 
[7.] F.A. Miranda, C.H. Mueller, R.E. Treece, T.V. Rivkin, J.B. Thompson, H.R. Moutinho, M. Galberth, and C.T. Rogers, Integrated Ferroelectrics, 14, 173 (1997).

[8.] C.H. Mueller, R.E. Treece, T.V. Rivkin, F.A. Miranda, H. R. Moutinho, A. Swartzlander-Franz, M. Dalberth, and C.T. Rogers, to be published in IEEE Trans. Appl. Supercond. (spring 1997).

[9.] S.K. Koul and B. Bhat, IEEE MTT-S Digest, 489 (1981).

[10.] R. Crampagne, M. Ahmadpanah, and J-L. Guiraud, IEEE Trans. Microwave Theory Tech., 26, 82 (1978).

[11.] Cheah, J.Y.C., RF Design, 11, 99 (1991).

[12.] Howald, R.L., Microwaves \& RF, 12, 97 (1993).

[13.] A. Khanna and Y. Garault, IEEE Trans. Microwave Theory Tech., 31, 261 (1983). 



\begin{tabular}{|c|c|c|c|c|}
\hline \multicolumn{3}{|c|}{ REPORT DOCUMENTATION PAGE } & & $\begin{array}{l}\text { Form Approved } \\
\text { OMB No. 0704-0188 }\end{array}$ \\
\hline \multicolumn{5}{|c|}{ 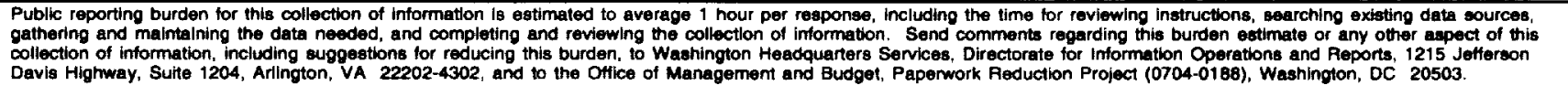 } \\
\hline 1. AGENCY USE ONLY (Leave blank) & $\begin{array}{r}\text { 2. REPORT DATE } \\
\text { May } 1997\end{array}$ & \multicolumn{3}{|c|}{$\begin{array}{l}\text { 3. REPORT TYPE AND DATES COVERED } \\
\text { Technical Memorandum }\end{array}$} \\
\hline \multicolumn{3}{|c|}{$\begin{array}{l}\text { 4. TITLE AND SUBTITLE } \\
\text { Thin Film Multilayer Conductor/Ferroelectric Tunable Microwave Components } \\
\text { for Communication Applications }\end{array}$} & \multirow{2}{*}{\multicolumn{2}{|c|}{$\begin{array}{l}\text { 5. FUNDING NUMBERS } \\
\text { WU-632-50-5D }\end{array}$}} \\
\hline \multicolumn{3}{|c|}{$\begin{array}{l}\text { 6. AUTHOR(S) } \\
\text { Félix A. Miranda, Robert R. Romanofsky, Frederick W. Van Keuls, } \\
\text { Carl H. Mueller, Randolph E. Treece, and Tania V. Rivkin }\end{array}$} & & \\
\hline \multicolumn{3}{|c|}{$\begin{array}{l}\text { 7. PERFORMING ORGANIZATION NAME(S) AND ADOAESS(ES) } \\
\text { National Aeronautics and Space Administration } \\
\text { Lewis Research Center } \\
\text { Cleveland, Ohio } 44135-3191\end{array}$} & \multicolumn{2}{|c|}{$\begin{array}{l}\text { B. PERFORMING ORGANIZATION } \\
\text { REPORT NUMBER } \\
\text { E-10695-1 }\end{array}$} \\
\hline \multicolumn{3}{|c|}{$\begin{array}{l}\text { 9. SPONSORINGMONITORING AGENCY NAME(S) AND ADDRESS(ES) } \\
\text { National Aeronautics and Space Administration } \\
\text { Washington, DC 20546-0001 }\end{array}$} & \multicolumn{2}{|c|}{$\begin{array}{l}\text { 10. SPONSORINGMONITORING } \\
\text { AGENCY REPORT NUMBER } \\
\text { NASA TM-107456 }\end{array}$} \\
\hline \multicolumn{5}{|c|}{$\begin{array}{l}\text { Prepared for the 9th International Symposium on Integrated Ferroelectrics sponsor } \\
\text { Santa Fe, New Mexico, March 2-5, 1997. Félix A. Miranda, Robert R. Romanofsk } \\
\text { Lewis Research Center; Carl H. Mueller, Randolph E. Treece and Tania V. Rivkin, } \\
\text { Responsible person, Félix A. Miranda, organization code 5620, (216) 433-6589. }\end{array}$} \\
\hline \multicolumn{3}{|c|}{$\begin{array}{l}\text { 12a. DISTRIBUTION/AVAILABILITY STATEMENT } \\
\text { Unclassified - Unlimited } \\
\text { Subject Category } 76 \\
\text { This publication is available from the NASA Center for AeroSpace Information, (301) } 621-0390\end{array}$} & \multicolumn{2}{|c|}{ 12b. DISTRIBUTION CODE } \\
\hline \multicolumn{5}{|c|}{ 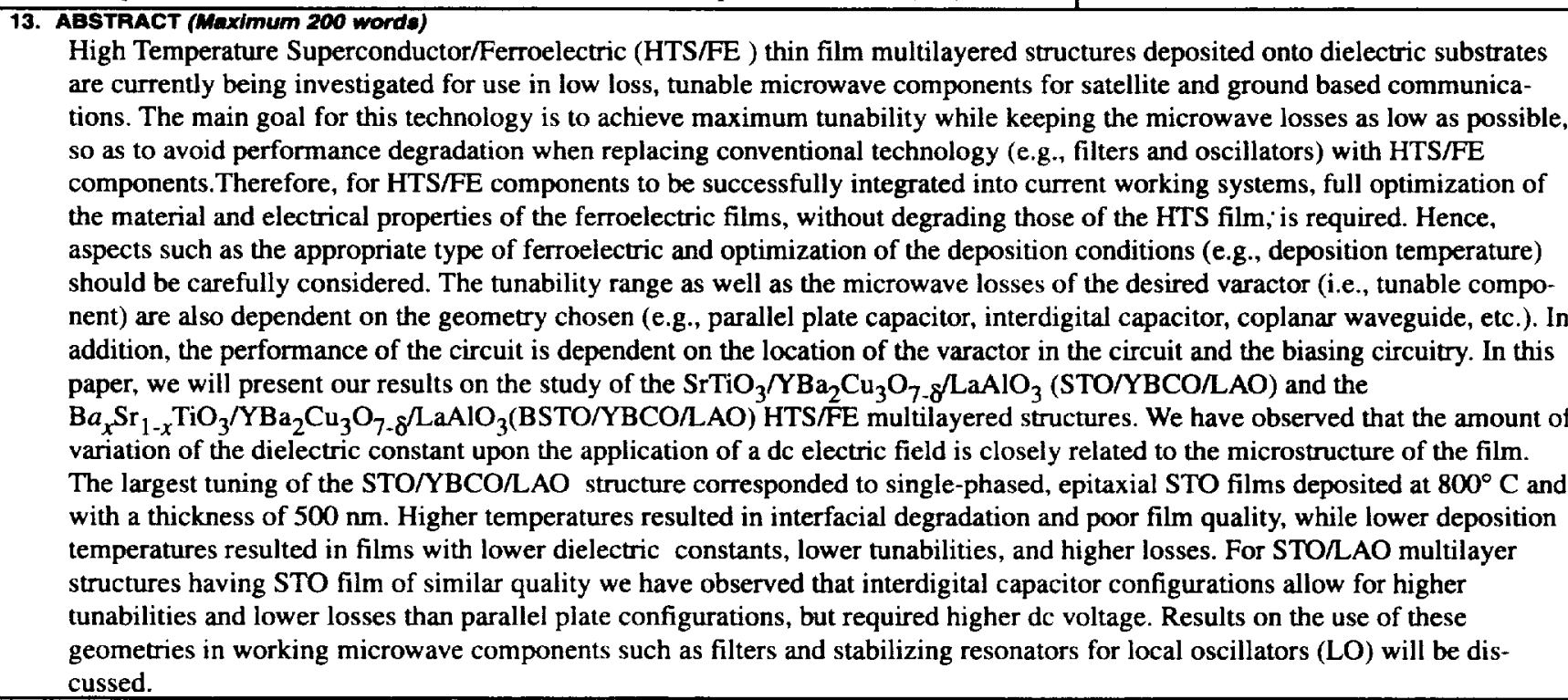 } \\
\hline \multirow{2}{*}{\multicolumn{4}{|c|}{$\begin{array}{l}\text { 14. SUBJECT TERMS } \\
\text { Ferroelectric films; HTS thin films; Dielectric constant; Loss tangent; K-factor; Phase } \\
\text { shifters; Local oscillator }\end{array}$}} & \begin{tabular}{|c|} 
15. NUMBER OF PAGES \\
18
\end{tabular} \\
\hline & & & & 16. PAICE CODE \\
\hline $\begin{array}{l}\text { 17. SECURITY CLASSIFICATION } \\
\text { OF REPORT } \\
\text { Unclassified }\end{array}$ & $\begin{array}{l}\text { 18. SECURITY CLASSIFICATION } \\
\text { OF THIS PAGE } \\
\text { Unclassified }\end{array}$ & $\begin{array}{l}\text { 19. SECURITY CLASSIFIC } \\
\text { OF ABSTRACT } \\
\text { Unclassified }\end{array}$ & & 20. LIMITATION OF ABSTRACT \\
\hline NSN 7540-01-280-5500 & & & & $\begin{array}{l}\text { dard Form } 298 \text { (Rev. 2-89) } \\
\text { ribed by ANSI Std. Z39-18 } \\
02\end{array}$ \\
\hline
\end{tabular}

